\title{
Ideological representations and Theme- Rheme analysis in English and Arabic news reports: a systemic functional approach
}

\author{
Lorena Potter
}

Correspondence:

lorenapott@yahoo.com

Hull, UK

\begin{abstract}
On 14 February 2005, the Lebanese Prime Minister, Rafiq al-Hariri, was killed along with 22 others in a massive car bomb in Beirut. His assassination provoked an international outcry, which ended the 30-year presence of Syria and led to the withdrawal of its troops from Lebanon. This paper explores the different representations of Syria in news reports following the investigation into Hariri's murder. The main aim is to examine the efficacy of Halliday's systems of THEME and INFORMATION in detecting ideological representations in the news. By ideological representations, we refer to the sociallyshared meanings, beliefs and opinions expressed by mainstream news media regarding the portrayal of Syria and its link to the attacks in Lebanon. This paper, which is an extract from my doctoral thesis, is the first attempt to adopt Halliday's functional model of Theme-Rheme in Arabic and apply his understanding of the clause as a message to English and Arabic news reports. The analysis compares and contrasts the thematic and information structures in 14 reports (7 in English and 7 in Arabic), which were published between 25 and 27 September 2006 by mainstream online news media, including Al-Jazeera and the British Broadcasting Corporation. The news sources provide English and Arabic versions allowing for a comparable analysis of structure, content and style. The results of the analysis confirm that Halliday's systems of THEME and INFORMATION are effective tools to unlock the meaning-potential in Arabic clauses and detect underlying ideologies in English and Arabic news reports.
\end{abstract}

Keywords: Theme-Rheme, Given-New, Arabic, News reports, Ideological representations

\section{Introduction}

\section{Theme and ideological representations in the news}

Elements in thematic position attract the readers' attention more than elements in rhematic position, as noted by Halliday (2004). The order of Theme and Rheme and their organization in the clause as a message are not arbitrary or value-free. They can be manipulated along with units of information, Given and New, to achieve a rhetorical purpose and reflect a specific angle of telling a story (Halliday 2004). In media discourse, writers select the thematic elements in news reports in general, and news headlines in particular, to attract the readers' attention to what they consider important and newsworthy (Khalil 2000). This paper investigates the efficacy of Halliday's systems of THEME and INFORMATION in English and Arabic news reports. It attempts to unlock the meaning-potential of the clause as a message and

(c) 2016 Potter. Open Access This article is distributed under the terms of the Creative Commons Attribution 4.0 International License (http://creativecommons.org/licenses/by/4.0/), which permits unrestricted use, distribution, and reproduction in any medium, provided you give appropriate credit to the original author(s) and the source, provide a link to the Creative Commons license, and indicate if changes were made. 
uncover the socially-shared meanings, beliefs, and opinions, or what we refer to as ideological representations, regarding the way Syria is presented by mainstream news media.

\section{Data description}

On 14 February 2005, the Lebanese Prime Minister, Rafiq al-Hariri, was killed along with 22 others in a massive car bomb in Beirut. His assassination provoked an international outcry, which ended the 30-year presence of Syria and led to the withdrawal of its troops from Lebanon. The killings in Lebanon, which were widely blamed on Syria, were investigated by the United Nations. However, these investigations have not yet led to any final judgment on who carried out the attacks. This study focuses on the murder investigation of Rafiq al-Hariri and the ideological representations of Syria in relation to his killing. Using Halliday's systems of THEME and INFORMATION, this paper analyses 14 news reports (7 in English and 7 in Arabic), which were published between 25 and 27 September 2006 by 7 mainstream online news media. The sources include 4 English and Arabic international news media: the British Broadcasting Corporation (BBC), Al-Jazeera, Alarab and the Cable News Network (CNN). They also include 2 national news media from Syria, Tishreen/Syria Times and the Syrian Arab News Agency (SANA), and 1 from Lebanon, the Al-Manar. These media provide written reports for English and Arabic speakers enabling a comparable analysis of content, structure and style in both languages. The analysis will help to identify whether news presentation differs according to language, i.e. the Arabic-language news reports present news differently from the English-language news reports, or whether it differs according to the media, i.e. Arabic sources, such as Al-Jazeera and Alarab, present the news differently from the English sources, such as the BBC and the CNN. The analysis finds that, regardless of their source, the English-language news reports tend to present Syria negatively in relation to Lebanon and Hariri's murder, whereas the Arabic-language news reports tend to present a positive picture of Syria. An exception is, however, found in the analysis of the English- and Arabic-language reports from the Syrian news sources. A positive representation of Syria is highly emphasized in both versions, as one would expect since the Syrian mainstream news media are state-run. The analysis concludes that the language in which these reports are written, rather than their sources, can affect and reflect the readers' perception and interpretation of social realities in the news.

\section{Original contributions}

Although many studies have been conducted in the fields of ideology and news discourse (e.g. Fairclough 1995, Fowler et al. 1979, Fowler 1991, Hodge and Kress 1993 and van Dijk 1998), very few have attempted to investigate the roles of Theme and Rheme in English and Arabic news reports. Most Arab grammarians analyse Theme and Rheme in Arabic by applying the Traditional Arab Grammarians' approach (TAGs), which allows only for the analysis of one type of clause, namely the nominal clause. Very few modern Arab scholars have attempted the Functional Sentence Perspective approach (FSP) to analyse both nominal and verbal clauses in Arabic. Discussion and reviews of these approaches are provided later in the section of Traditional and Modern Treatment of Theme and Rheme in Arabic. There has been no attempt, before 
now, to empirically apply Halliday's system of THEME and INFORMATION to Arabic. This study is, therefore, the first attempt.

- To apply Halliday's Theme-Rheme structure to Arabic verbal and nominal clauses.

- To compare and contrast the thematic and information structures in English and Arabic.

- To investigate the efficacy of Halliday's systems of THEME and INFORMATION in detecting underlying ideologies and representations in news reports.

This study has taken a tentative first step to consider and analyse the initial verb and the following noun as the unmarked Theme in Arabic, as will be discussed shortly. Arabic nominal clauses are considered marked along with Complement- and Adjunct-initial clauses. The study also incorporates Halliday's definitions and categorization of Theme, Rheme, Given and New information with different concepts from Critical Discourse Analysis (CDA), such as ideology, thematization and the discursive processes of naturalization, rationalization, habitualization, persuasion and management of information. Thematization is defined as a transformational process by which some parts of the clause, such as a Complement or an Adjunct, are placed in initial position (Fowler et al. 1979). The process of thematization is related to Halliday's model of Theme-Rheme and the selection of these elements in the clause. By analysing thematization and Halliday's systems of THEME and INFORMATION, we hope to be able to detect underlying social representations regarding the way Syria is portrayed in the English and Arabic news reports. The concept of naturalization refers to the process where ideologies become part of everyday life and everyday social experience to the degree that people will not realize that they have them. Hence, ideologies become 'common-sense' assumptions and 'takenfor-granted' beliefs (Fairclough 1985, Fowler 1996, Simpson 1993 and van Dijk 1998). The second process, rationalization, takes place when dominant ideologies become ingrained in everyday social practice so much so that people rationalize them as common-sense beliefs about the way things are and how they should be (Simpson 1993). The third discursive process, habitualization, describes a tendency whereby ideological beliefs, social practices and experience become unchallengeable, 'automatic', 'uncritical' and 'habitual' (Fowler: 1996). Other forms of ideologies also manifest through the use of persuasive discourse to win the readers' consent and shape their opinions. Persuasive techniques include the use of emphasis, direct repetition of statements, modification, positive and negative association and interpretation (Hawthorn 1987 and van Dijk 1998). Association, also known as 'implicature' or 'suggestion', refers to information which is not explicitly present in a text, but rather implied based on particular opinions and specific knowledge of the news situation (van Dijk 1988). Within the systems of THEME and INFORMATION, unmarked and marked structures can also be used as persuasive devices to project certain ideological representations, as will be discussed later in the Findings and Discussion section. The last discursive process, management of information, refers to the role of news media as social institutions and the various mechanisms they use to engineer the public consent and manage their opinions. These mechanisms include restricting the flow and access of information by means of secrecy, security and censorship, hence only certain forms of knowledge and opinions are allowed, expressed and widely circulated (Fairclough 1995, Fairclough and Wodak 1997, Harré 1985, Hawthorn 1987, Herman and Chomsky 
2002, Robins et al. 1987, and van Dijk 1997; 1998). Management of information can also include selecting certain linguistic terms as Themes or Rhemes and presenting certain information as Given or New. These choices can help to project certain views and shape social representations in the news. By analysing these processes in relation to Halliday's model of Theme-Rheme and Given-New information, we hope to shed some light on news media practices, which shape social meanings and influence the readers' perception and interpretation of the news.

\section{Background: the Hallidayan approach to Theme-Rheme analysis}

According to Halliday (2004), the structure of a clause embodies three distinct strands of meaning: a clause as a message, a clause as a representation and a clause as an exchange. This paper focuses on the first line of meaning and the interplay between the systems of THEME and INFORMATION. The aim is to investigate the efficacy of Halliday's systems in detecting underlying ideologies in English and Arabic news reports. The structure which carries the first line of meaning, a clause as a message, is known as the thematic structure. It comprises two functional units: Theme and Rheme. In English, these units are signalled by position and order in the clause. A Theme always occupies the first position in a clause and is followed and commented on by a Rheme (Halliday 1967; 2004).

\section{Types of themes}

As a general rule, the Theme of a clause is realized by 'the first group, or phrase, which has some function in the experiential structure of the clause' (Halliday 2004: 66). By experiential, Halliday refers to the second strand of meaning, namely a clause 'as a representation of some process in ongoing human experience' (Halliday 2004: 59). The three experiential elements of a clause are: the process, the participants and the circumstantial factors. The elements which are assigned a thematic status in a clause must contain one, and only one, experiential element. This element is referred to as the topical Theme. There may also be other elements in the clause which occur initially but are not integrated within the experiential structure of the clause. These are termed textual and interpersonal Themes. Both textual and interpersonal Themes are 'natural Themes', i.e. they are thematic by default. A Theme of a clause thus contains only one topical Theme functioning as a Subject, a Complement or an Adjunct and one or more textual and interpersonal Themes. This is illustrated in Table 1. A topical Theme can function as a full Theme, whereas textual and interpersonal Themes function as part of a Theme.

\section{Theme and mood}

The element which is typically chosen as Theme in an English clause depends on the choice of mood: declarative, interrogative or imperative. Since the data belongs to the expository text-type, within which mainly statements exist, we shall confine our

Table 1 Multiple Themes

\begin{tabular}{|c|c|c|c|c|c|}
\hline But & then & finally & to my surprise & Jean & joins \\
\hline textual & textual & textual & interpersonal & topical & \\
\hline Theme & & & & & Rheme \\
\hline
\end{tabular}


description to the declarative mood. The most common type of Theme in an English declarative clause is a nominal group functioning as a Subject. Halliday (2004) refers to this as the unmarked Theme. Any variation of this type is considered marked. Halliday (2004) classifies marked Themes into three main categories starting from least towards most marked: fronted Theme, predicated Theme and identifying Theme. The degree of markedness expressed by a fronted element is measured by its mobility, i.e. the more mobile an element is, the less marked it will be in thematic position (Baker 1992). In this sense, fronted Complements are more marked than fronted Adjuncts and less marked than fronted Predicators. Unlike an identifying Theme, a predicated Theme is mostly associated with New information in the clause (Halliday 2004: 95). A clause may contain more than one layer of Theme depending on its type, dependent or independent. Only the higher layer of Theme, namely the main clause - or what Halliday (2004: 72) terms as a 'free major declarative clause' - will be considered as the unit of analysis in this study.

\section{The system of THEME and the system of INFORMATION}

The THEME and INFORMATION systems are semantically related. Elements in both systems are selected and organized by writers, who can then manipulate the clausal and information units to create social meanings and influence public opinion. Halliday (2004: 93) states that:

Within any given scenario, or set of contextual conditions, the speaker can exploit the potential that the situation defines, using thematic and information structures to produce an astonishing variety of rhetorical effects. He can play with the system, so to speak. A very frequent type of linguistic-game playing is the use of these two systems to achieve complex manoeuvres of putting the other down, making him feel guilty and the like.

However, the structure of INFORMATION is not of the clause. The INFORMATION system is of a separate grammatical unit, called the information unit (Halliday 1967). Ideally, a unit of information consists of two elements: Given and New. The first element, which is optional, refers to what part of the message is known, or predictable. The latter, which is obligatory, refers to what part of the message is unknown, or unpredictable. A single unit of information, also known as a message block, can be mapped into a clause, less than a clause (morpheme, word, or phrase), or two or more clauses. When parallel to the clause, an information unit represents the default, or unmarked, condition. Writers can choose where a unit of information begins and where it ends. They can also choose to present unknown information as Given and known information as New (Halliday 2004). These choices can be geared towards projecting a particular point of view and conveying a certain message. Nonetheless, the writers' choices are measured against the social background of what has happened before. Ultimately, the context of situation helps to determine which element the readers consider as Given and which as New (Baker 1992, Chafe 1976, Halliday 1976; 2004).

In addition to the context of situation, textual features in written discourse help to identify Given and New elements. Units of information are realized by syntactic devices, such as punctuation, cleft-structures, emphasis, recoverability, predictability, 
saliency and position (Halliday 2004). According to Halliday (1967, 2004), the default, unmarked, sequence of information is that of Given followed by New. When a unit of information only consists of the New element, it is then considered as marked. Moreover, when both THEME and INFORMATION systems are unmarked, the Theme falls within the Given, while the Rheme falls within the New. At the global level of news reports, information presented in the headline and lead paragraph(s) is usually New, whereas information presented last in the report is background, old, or Given (Khalil 2000). Tense (past/present) and aspect (perfect/imperfect) can also determine whether an element is Given or New (Khalil 2000). Past tense, for example, can encode known information and future tense can encode unknown information.

\section{Towards a functional model of Theme-Rheme in Arabic}

\section{The structure of the Arabic language: verbal and nominal clauses}

Unlike English, Arabic has a relatively free word-order, which permits different constituents, Predicator, Subject, Complement and Adjunct, to occupy different positions in the clause (Abdul-Raof 1998). This is mainly due to the fact that Arabic has an inflection, or case-marking system, which helps to clarify the syntactical relations between constituents. In the declarative mood, Arabic uses two types of clauses: verbal and nominal (Aziz 1988). The former contains an initial lexical verb in its predication and has the pattern V-SBJ-COMP (verb-Subject-Complement). The latter consists of an initial noun functioning as a Subject followed by a Complement (COMP), or a lexical verb. According to Arab linguists, verbal and nominal clauses are used differently in Arabic. Wright (1974) notes that Arabic speakers use verb-initial clauses to relate events and actions and nominal clauses to describe people and objects. In their wide-range analysis of both types, Parkinson (1981) and Abdul-Raof (1998) conclude that verbal clauses are more commonly used in news reports, whereas nominal clauses are more commonly used in editorials. Hatim (1989) also notes that the choice between verbal and nominal clauses in Arabic is closely bound up with text-types and text-functions, i.e. the interaction between the message, the producer and the receiver. In his words (1989: 144):

Our conclusions point to the fact that the choice is ultimately related to text-type.

The verbal clause structure tends to predominate in non-evaluative, expository texts, while the nominal structure is typically of evaluative, argumentative texts.

These studies may entail that verbal clauses represent the unmarked structure in Arabic news reports, but represent marked structures in editorials. However, this supposition is not necessarily valid, as frequency alone cannot account for the basic structure in Arabic. Traditional Arab Grammarians (TAGs) provide four tenets to determine the most common syntactic order in Arabic: frequency, neutrality, ambiguity and interrogatives (for details see Abdul-Raof 1998). They conclude that the sequence verb-Subject-Complement-Adjunct (V-SBJ-COMP-ADT) meets all tenets, therefore, 'the verbal clause is the basis of expression in Arabic' (Al-Jarim 1953: 347). We also agree with the TAGs' argument and consider the verbal clause as the unmarked structure in Arabic, regardless of text-types, text-functions or genre. 
Traditional and modern treatment of Theme and Rheme in Arabic

Traditional Arab Grammarians (TAGs), namely Basra and Kufa Schools, have defined the mubtada, or theme, in Arabic as a definite pre-verbal, or initial, noun displaying the nominative case marker $u$, and the khabar, rheme, as whatever comes after the mubtada'. The TAGs' approach to theme and rheme analysis has been criticized for a number of reasons. Firstly, modern Arab grammarians criticize TAGs for analysing theme and rheme grammatically, rather than semantically or pragmatically. According to Abdul-Raof (1998), theme and rheme in classical Arabic grammar are morphosyntactic notions which rely heavily upon case marking. Moutaouakil (1989) also criticizes the TAGs' association of theme with definiteness. Theme is presupposed as known or old information despite the fact that there are cases where theme can display unknown information in clause-initial position. Secondly, traditional, and most modern, Arab grammarians have been criticized for analysing theme and rheme in Arabic on a sentence basis. Abdul-Raof (1998) points out that the analysis has so far been confined to isolated sentences with no consideration of text-types, genre, or the contextual situation of the real event. All three aspects are taken into consideration in this paper. Thirdly, in the view of TAGs, conjuncts and disjuncts are not integrated within the structure of the Arabic clause. Conjuncts and disjuncts do not function as theme or rheme nor do they comprise part of the thematic structure of the Arabic nominal clause. Moreover, fronted Adjuncts and fronted Complements whose use is marked in Arabic are not fully recognized by TAGs. TAGs account for the change of word sequence in nominal but not verbal clauses. For example, Adjuncts in nominal clauses, whether in front or final position, are considered as rheme or part of the rhematic elements, whereas Complements are treated the same in initial and final position. Finally, and most importantly, TAGs and most Arab linguists, including Abdul-Raof 1998 and Moutaouakil 1989, analyse theme as a nominal phrase, which occurs in nominal but not verbal clauses. News reports, like any text-type or genre in Arabic, contain both verbal and nominal clauses. We argued that verbal clauses, which are more frequently used in news reports, represent the basic, unmarked, structure in Arabic. However, these structures are not accounted for in terms of theme and rheme. The latter elements are considered as attributes of declarative nominal clauses, whereas imperative, interrogative and verbal clauses are considered themeless. Using approaches such as described to perform a comparative study of thematic structures in Arabic, or Arabic and English, would produce incomprehensive and incompatible results. Hence there is a need to find and develop a new approach by means of which all types of Arabic clauses, verbal and nominal, can be analysed.

A few modern Arab scholars, namely Abu-Ghazaleh (1983), Abu-Mansour (1986), Aziz (1988) and Hatim (1989) manage to overcome this problem by adopting the Functional Sentence Perspective approach (FSP) (for details on FSP see Firbas 1966; 1974). This approach allows them to analyse both verbal and nominal clauses and account for the movement of constituents in the clause. However, their analysis of Arabic, especially the verb, remains inconsistent, confusing and subjective. On the one hand, Aziz (1988) and Hatim $(1989$; 1990) consider the verb (modal, auxiliary and lexical) as a transitional element, ${ }^{1}$ even when it is communicatively more important than the Subject - a treatment which contradicts the FSP's definition of Transition. In verbal clauses consisting of only two elements, V-SBJ, Aziz (1988) analyses the verb as Rheme and the Subject as 
Theme. In his view, this is because in the unmarked verbal clause the verb is communicatively more important than the Subject. Aziz's analysis suggests that New information comes first and is followed by Given information in unmarked verbal clauses. His claim contradicts the FSP approach in which Theme precedes and is followed by Rheme in basic and most common structures. On the other hand, Abu-Ghazaleh (1983) analyses verbs mostly as Theme in narrative spoken Arabic, while Abu-Mansour (1986) analyses them as either Theme or Rheme, depending on their degrees of Communicative Dynamism (CD). As in English, identifying Theme, Transition and Rheme in Arabic by means of degrees of $C D$ is subjective, impractical and relies heavily on the writers and readers' interpretation of the text (for criticisms of CD see Adjémian 1978 and Chafe 1974). Even with the presence of the context of situation, drawing a sharp line between sentence elements in terms of the degree of CD they carry may be inaccurate as it differs from one interpretation to another. There are no common and objective grounds on which to test whether both writers and readers regard a certain element as carrying exactly the same degree of Communicative Dynamism. In order to avoid the subjective analysis of Theme and Rheme, we suggest splitting the two levels of clause and information, by following Halliday's systemic functional model. This enables a more objective analysis of Theme-Rheme and Given-New structures. Moreover, the FSP approach does not provide a comprehensive and objective toolkit with which to analyse sentence constituents in Arabic with respect to Firbas's notion of CD. There is no single objective procedure by which modern Arab scholars can exactly identify Theme and Rheme. Finally, modern Arab scholars seem to pay little attention to the syntactic and textual devices available in Arabic to indicate marked structures. Such is the case with cleft and pseudo-cleft structures and the transformational process of thematization. Therefore, it remains essential to identify an objective and functional model by means of which all types of Arabic clauses, verbal and nominal, can be analysed in terms of Theme and Rheme and constituents can be accounted for in clause-initial position. Halliday's system of THEME seems to find an answer. Although, Halliday's systemic functional approach has been applied to languages other than English, such as French, Spanish and Japanese - McCabe (1999), Caffarel (2006) and Teruya (2006), respectively - up until now, no attempt has been made to apply the systems of THEME and INFORMATION to Arabic.

\section{Applying Halliday's model to Arabic}

Baker (1992) criticizes the Hallidayan system for its failure to relate the definition of Theme and Rheme to verb-initial languages, such as Arabic. However, applying Halliday's model to languages with free word-order does not seem overly problematic. Halliday (2004) and Baker (1992) discuss some rare cases in English where verbs can occur initially as marked Themes in declarative clauses. Baker (1992: 134) presents the following example: 'They promised to publicize the book in China, and publicize it they did'. The verb, 'publicize', in the second main clause functions as the Theme. In dealing with verb-initial languages, what is marked in one language, such as English, is unmarked in another, such as Arabic. Thus, we consider the verbal clause with the basic sequence: Predicator-Subject-Complement-Adjunct as unmarked and parallel to Subject-Predicator-Complement-Adjunct in English. 


\section{Theme and Rheme re-defined}

Following Halliday's definition, an unmarked Theme in Arabic can be represented by the initial experiential element functioning as the Predicator, i.e. the lexical verb. However, in order to conduct a comparative analysis of thematic structures in Arabic and English news reports considering the Predicator, alone, as an unmarked Theme in Arabic will present the following challenge. Due to the syntactic difference between the two languages, verbs, alone, as unmarked Themes in Arabic will be measured against nominal, prepositional and adverbial phrases in English. Such analysis would produce incompatible and less meaningful results. To overcome this challenge, we propose including the following experiential element, namely the Subject, as part of the unmarked Theme. This proposition can be supported by Halliday's thematic analysis of nondeclarative clauses. In imperative and yes/no interrogative clauses, Halliday (2004) considers both the verb and the Subject to function as the unmarked Theme. The application of Halliday's systemic functional model in Spanish and Japanese, also, supports our proposition. In Japanese, for example, an unmarked Theme usually comprises two experiential components, namely a circumstantial Adjunct and a Subject (Teruya 2006). The reason is that Adjuncts in Japanese are thematic by default. Since the verb assumes a default thematic position in Arabic, the same argument is valid here. Moreover, Spanish, which has a relatively free word-order, allows for verb-initial clauses in certain constructions. In this case, McCabe (1999) suggests that an initial verb, and not its elided Subject, is analysed as Theme, whereas Munday (1997) considers the elided Subject pronoun as Theme. In his study on English and Spanish translation, Munday (1997) argues that the syntactic difference between the two languages would produce incompatible results in his source and target texts.

\section{Marked themes}

Following Halliday's (2004) classification of marked Themes in English, marked Themes in Arabic can be classified into three main types starting from the least towards the most marked: fronted Theme, predicated Theme and identifying Theme. The first type includes fronted, or pre-verbal, Subjects, fronted Adjuncts, and fronted Complements. A Complement, or an Adjunct, which occurs immediately after a lexical verb and before a Subject, is also considered part of a marked Theme. Like English, Arabic has cleft and pseudo-cleft structures (for details see Abdul-Raof 1998). Judging by the mobility of these constituents fronted Subjects and fronted Adjuncts are the least marked in Arabic, followed by cleft, then, pseudo-cleft structures. Fronted Subjects are commonly used in Arabic news headlines, whereas cleft and pseudo-cleft structures are rarely used, unless they are part of quoted speech in the report.

\section{The INFORMATION system in Arabic}

As in English, Given and New information in Arabic written discourse can be determined by recoverability, predictability, saliency, position, tense and aspect. According to Khalil (2000), Arabic syntactic devices, such as the empty verb kāna and its 'sisters', help to determine whether a constituent is previously mentioned, or not. Moreover, the free movement of constituents in the Arabic clause helps largely to indicate where a 
unit of information begins and where it ends. This view is supported by the works of Aziz (1988) and Hatim (1989) who claim that Arabic responds better to the principles of CD. In other words, in Arabic it is relatively easy to determine which element is the Given and which is the New. Following Halliday's (2004) categorization, a unit of information consists of two elements: Given followed by New. In its unmarked condition, we consider a unit of information in Arabic as parallel to a clause with the sequence Predicator-Subject-Complement-Adjunct. Any variation of this order most likely indicates a new unit of information, taking into account the situational context.

\section{Findings and discussion}

This section analyses 14 English and Arabic news reports on the topic of Hariri's murder investigation in 2006 by applying Halliday's systems of THEME and INFORMATION. The analysis explores the relationship between the different choices of Theme, Rheme, Given information, New information, marked structures and the processes of thematization, naturalization, habitualization, rationalization, persuasion and management of information. The aim is to explore the ideological representations of Syria in relation to Hariri's murder in these reports. The section starts with analysing the headlines then the body of the reports. All main clauses in the English and Arabic news reports are analysed. However, only those which signal the reports' stance on Syria are presented and discussed here.

\section{News headlines}

News headlines catch the readers' eyes first. The Theme of a news headline comes first not only at the micro-level of the clause, but also at the macro-level of the text. It is possible for both Theme and Rheme elements in a news headline to convey New information, since a news report has to start somewhere and information placed at the beginning of a report may not be recovered nor mentioned before. Halliday (2004: 89) uses the term 'discourse-initiating units' to describe the elements with which a discourse starts. By starting the analysis here, we hope to find a rich ground for testing the efficacy of Halliday's systems of THEME and INFORMATION in detecting ideological representations of Syria in relation to Hariri's murder investigation.

\section{Thematization}

1. Syria's cooperation appreciated (Syria Times, English headline)

The thematic elements are underlined and New information is presented in boldface in all the examples here. The Syria Times report focuses on 'Syria' and its 'cooperation' by placing them initially at the global level of discourse, i.e. the news summary. At the local level, the placement of 'cooperation' at the beginning of the clause is intended to convince the readers that Syria's good intentions and efforts are predicted, or known, information, even though there has been no mention of its cooperation in previous reports. New information, or the information focus, in the headline is conveyed by the Rheme, 'appreciated', which positively modifies the Theme, 'Syria's cooperation'. Right from the beginning, the readers of this report are encouraged to infer the innocence of 
Syria and interpret any references made by other news media to its involvement in Hariri's murder as unfounded allegations. The interplay between the systems of THEME and INFORMATION, thematization and modification helps to project a positive representation of Syria in example 1.

\section{Marked thematic structure}

Similarly, the analysis of the Arabic-language headlines from Tishreen, Al-Manar, Al-Jazeera and Alarab reveals a positive representation of Syria, as illustrated in the examples below ${ }^{1}$ :

2. المساعدات السورية كانت مرضية (Tishreen, Arabic headline)

Transcript: al-musā adātu as-sūrīah kānat murḍah

Gloss: the-cooperation the-Syrian-adj was satisfactory

Translation: Syria's cooperation was satisfactory

3. براميرتز يعتبر تعاون سوريا مرض (Al-Manar, Arabic headline)

Transcript: Brammertz yả tabiru ta āwna sūrya murdín

Gloss: $\underline{B r a m m e r t z}$ consider cooperation Syria-gen satisfactory

Translation: Brammertz considers Syria's cooperation satisfactory

4. الوحققالدولي يثني على تعاون سوريا (Alarab, Arabic headline)

Transcript: al-muhaqiqu ad-dūalīu yuthnī alá ta āwni sūrya

Gloss: the-investigator the-international compliment on cooperation Syria

Translation: The UN investigator compliments Syria's cooperation

5. سوريا تصف تقرير براميرتس بالإيجابي (Al-Jazeera, Arabic headline)

Transcript: sūrya tașifu taqrīra Brammertz bi-lìjābì

Gloss: Syria describe report Brammertz in-positively

Translation: Syria receives Brammertz report positively

The unmarked syntactic order for reporting the news in Arabic is Predicator-SubjectComplement. In news headlines, however, Arabic reports use nominal clauses, SubjectPredicator-Complement, to attract the readers' attention to the main topic of events (Cantarino 1974 and Keenan and Schieffelin 1976). Following Halliday's definition of Theme and his categorization of markedness, this study considers Arabic news headlines as marked thematic structures. In examples 2, 3 and 4, 'Syria's cooperation' is perceived as known information, which has been discussed in previous reports. 'Cooperation' is modified by the adjective, 'satisfactory', in examples 2 and 3 and pre-modified by the verb, 'compliment', in example 4. In example 5, the adverb, 'positively', describes Syria's reception of the United Nations' investigation report. At the global level of discourse, these positive modifiers carry the information focus and aim to assert a good image of Syria and its efforts to assist with Hariri's murder investigation. The analysis of the 
systems of THEME and INFORMATION, marked thematic structures and positive modifiers helps to elucidate the ideological representation of Syria in the Arabic headlines.

\section{Unmarked information structure}

The Arabic-language headlines above are marked in terms of Theme-Rheme structure but are unmarked in terms of the information structure. Given information is presented first followed by New information. In examples 3 and 4, 'cooperation' functions as part of the rhematic elements and is presented as old information. The New information falls on the rhematic elements, 'satisfactory,' 'satisfactory', 'compliments' and 'positively' in examples 2, 3, 4 and 5 respectively. These elements are neither predicted nor mentioned in previous reports. The choice and organization of clausal and information elements in the Arabic headlines have a strong potential to strengthen the readers' belief in Syria as an unlikely suspect in Hariri's murder. The analysis of the unmarked information structure and the choice of certain linguistic terms as Given or New information strongly suggest a positive representation of Syria in the Arabic headlines. In other words, the interplay between the systems of THEME and INFORMATION identifies the ideological representation of Syria in the Arabic reports.

\section{Marked information structure}

In contrast with the previous Arabic headlines, the CNN English headline, example 6, displays a marked information structure, i.e. New-Given.

\section{New leads in Hariri's murder}

(CNN, English headline)

This report was published on 25 September 2006 and the murder of Rafiq al-Hariri took place on 14 February 2005. Since his assassination, the United Nations' investigation has been the subject of many news reports. Taking the context of situation into account, Hariri's murder is thus Given information. A careful examination of the English headline reveals that unknown information is conveyed by the adjective, 'new', and known information is conveyed by the following elements, 'leads in Hariri's murder'. The pre-modification of the thematic element, 'leads', suggests that previous evidence has been uncovered, which links Syria to Hariri's murder. This link is mentioned later in the CNN English report, as illustrated in example 7.

7. The United States has suggested that the government of Syria is behind the Hariri murder.

The above clause demonstrates the use of yet another marked information structure. New information, 'the United States', which is not mentioned before, is presented first and followed by Given information, 'has suggested that the government of Syria is behind the Hariri murder'. This association between the Syrian government and the assassination of Hariri is repeated 9 times in the CNN English report. The emphasis on Syria's implication indicates a process of persuasion to construe Syria as a possible perpetrator of Hariri's murder. The analysis of examples 6 and 7 demonstrates the relationship between the systems of THEME 
and INFORMATION and the use of marked information structures, modification, association and repetition as persuasive techniques to project a negative representation of Syria in the CNN English report.

\section{The body of the reports}

Social representations, or ideologies, have many forms. They can be expressed explicitly, such as those attributed to political leaders and religious authorities. Others can be implicit and embedded in the practices of every-day discourse (van Dijk 1998). Implicit ideologies, such as those which can exist in news reports, manifest through different processes. These include naturalization, rationalization, habitualization, persuasion and management of information (see critical discourse analysts such as Fairclough 1985, Fowler 1996, and Wodak 2001). The following sections will investigate these processes in relation to Theme-Rheme and Given-New structures in the body of the sample reports. The aims are to explore how social meanings are created and whether Halliday's systems of THEME and INFORMATION are capable of making explicit what is implicit and, thus, raising the readers' consciousness of underlying social representations of Syria in these reports.

\section{Naturalization, rationalization and habitualization}

Fairclough (1985: 751) notes that 'naturalization gives to particular ideological representations the status of common sense, and thereby makes them opaque, i.e. no longer visible as ideologies'. Simpson (1993: 6) also defines 'naturalization' as:

The way dominant ideologies become ingrained in everyday discourse. They become rationalized as 'common-sense' assumptions about the way things are and the way things should be. A process of naturalization takes place, to the extent that people are often no longer aware of the hierarchies and systems which shape their social interaction [Italics in original].

In other words, 'naturalization' is a 'rationalization' process whereby ideological beliefs become presupposed knowledge and 'common-sense' social representations. Fowler (1996) refers to the tendency whereby ideological beliefs become 'uncritical' as 'habitualization'. Fowler (1996: 12) defines 'habitualization' as:

A basic tendency in the psychology of perception (and by extension, knowledge and meaning). If experience is habitual, perception becomes automatic and uncritical... Habitualization is staleness of thought and language.

To put it differently, ideologies become 'naturalized,' 'rationalized' and 'habitualized' as 'common sense' when they are part of what people commonly think and believe. The analysis of the data reveals that the interplay between the systems of THEME and INFORMATION helps to give meanings to certain ideological processes and social representations. The following example from the Al-Jazeera English-language report elucidates this case:

8. Evidence found at the scene of the blast also included a tooth, probably of the bomber, which featured an unspecified 'distinguishing mark' on its crown, suggesting that he may not have been from Lebanon, the report said (Al-Jazeera English report). 
Although the term 'evidence' is New information, which is not mentioned before in the Al-Jazeera English report, the news producers choose to present it as Given information. This interpretation is supported by the initial position of 'evidence' and the presence of the thematically inherent conjunction, 'also'. New information, in example 8, is conveyed by the rhematic elements, 'tooth', 'unspecified distinguishing mark' and 'may not have been from' Lebanon. The choice of Theme and Rheme and their interplay with Given and New information suggest Syria's connection to Hariri's killing. The same report then states twice that 'evidence' was found which implicates Syrian officials and the Syrian Intelligence Services, see example 9 below. The association between 'evidence' and Syria can trigger a rationalization process where Syria is perceived as a logical perpetrator of the crimes committed in Lebanon. The analysis of example 8 demonstrates the relationship between the systems of THEME and INFORMATION and a process of rationalization to construe Syria negatively in the Al-Jazeera English report. This view is further supported by the analysis of example 9.

9. In one report, Mehlis had implicated ...Syria's military intelligence chief...

Both Theme and Rheme in example 9 convey Given information by virtue of the past tense 'implicated' and the perfect aspect 'had'. The sentence also displays a marked fronted Theme, i.e. the prepositional phrase 'in one report'. The factors of tense, aspect, marked thematic structure and context of situation indicate that the information in example 9 is Given, predicted and mentioned in previous reports. The use of marked thematic structure and the presentation of Given information indicate a process of habitualization. Syria's implication is relayed as taken-for-granted knowledge. The analysis of the report also reveals a process of naturalization, where the accusation against Syria is normalized and construed as a fact based on 'evidence'. It is noteworthy to mention that neither the English nor the Arabic news reports in the selected data mention any details of the nature of the 'evidence', which allegedly incriminates Syria, with the exception of the tooth in example 8. Examples 8 and 9 demonstrate the relationship between the systems of THEME and INFORMATION and the processes of naturalization, rationalization and habitualization to construe the ideological representation of Syria as the logical culprit of Hariri's murder.

\section{Persuasion: emphasis, repetition and modification}

Other forms of ideologies become manifest through the use of persuasive discourse to win the readers' consent and shape their opinions. Persuasive techniques include emphasis, direct repetition of statements, modification, association and interpretation (Hawthorn 1987 and van Dijk 1998). The analysis of the selected reports reveals cases where the mapping of the two systems of THEME and INFORMATION helps to elucidate and identify the relationship between persuasive processes and preferred social representations. In the case of the English reports, a negative social representation of Syria prevails in Al-Jazeera, Alarab, the BBC and the CNN. The term, 'evidence', for example, is repeated as predicted, or Given, information in thematic position throughout these reports. 'Evidence' is also pre-modified by adjectives, such as 'new', 'increasing', 'growing', 'amassing', 'mounting' and 'fresh', which mostly function as New information. 
The emphasis, repetition, pre-modification and distribution of Given-New information in the English reports indicate a process of persuasion to construe Syria as a perpetrator of Hariri's murder. This negative representation is clearly signalled in the CNN English report, as illustrated in example 6 above.

\section{Persuasion: marked thematic structures in Arabic}

In the same vein, the analysis of the Arabic news reports reveals the role of Halliday's systems of THEME and INFORMATION in identifying a different social representation of Syria. It indicates the use of marked thematic structures, in headlines and bodies of the reports, as a persuasive tool to draw Syria positively. Arabic news headlines, for example, are constructed by using nominal clauses, i.e. marked thematic structures. This practice not only attracts the readers' attention to the main topic of the news, but also helps to promote a certain social representation of Syria, as discussed earlier. Similarly, marked thematic structures are used in the body of the Arabic reports to influence the readers' perception of Syria as a victim of alleged accusation. The following example from the Alarab Arabic report demonstrates this case.

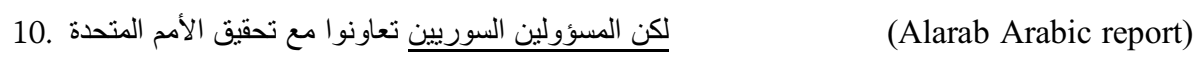

lakinna al-mas'ūlīn as-sūrīn ta āwanū máa taḩqiqi al-umami al-mutaḩidah However the-officials the-Syrians cooperate with investigation the-nations the-united Translation: However, the Syrian officials have cooperated with the UN investigation.

In terms of sequence and position, example 10 is the eighth main clause and occurs towards the middle of the Alarab Arabic report, which is titled 'The UN investigator compliments Syria's cooperation' (see example 5). The Theme, 'However, the Syrian officials', and the Rheme, 'have cooperated with the UN investigation', are Given information, because they are mentioned in previous clauses in this report, including the headline. Example 10 displays a nominal structure, which starts with a fronted Subject, 'Syrian officials', followed by a verb, 'have cooperated'. The most common sequence of elements in Arabic news reports is verb-Subject-Complement; hence, nominal clauses are considered here as thematically marked. The emphatic device, 'however', is an argumentative device, which is frequently used in editorials. The effect of using a nominal structure and an emphatic device in Arabic can be compared to the use of the emphatic 'do' before the verb in English. The analysis of example 10 indicates an emphasis on Syria's good endeavour, which is likely to prompt the readers into accepting Syria's innocence of Hariri's murder. This argument is further supported by the report's repetition of statements, which positively describe Syria's actions. Syria's 'cooperation' is repeated six times in this report and is associated with positive terms, such as the verb 'compliments' in the headline (example 5) and the adjective 'satisfactory' in example 11.
11. وصف براميرتس التعاون بأنه'مرض بثككل عام'
(Alarab Arabic report)

wasafa Brammertz at-tá āūna bi-annahu murdịi ${ }^{\mathrm{n}}$ bi-shakli ${ }^{\text {ne }}$ āmi $^{\mathrm{n}}$

described Brammertz the-cooperation in-that satisfactory in-form general

Translation: Brammertz described the cooperation as 'generally satisfactory'. 
'Satisfactory', which presents New information in example 11, is repeated three times in the Alarab Arabic report. The use of marked thematic structures, emphasis, association, modification and repetition of certain lexical terms indicates a process of persuasion to construe Syria positively. This representation is also relayed by the choice of Theme, Rheme, Given and New elements. Syria's cooperation is constantly repeated as Given information and modified by New information to emphasize its good effort. The analysis reveals the relationship between the systems of THEME and INFORMATION and a process of persuasion to construe Syria as a victim of allegations rather than a culprit of murder.

Similarly, the marked thematic structure in example 12 from the Tishreen Arabic news report implies a positive representation of Syria.

12. وكان الأمين العام للأمم المتحدة قد عبر عن شكره لسورية لتعاونها مع اللجنة (Tishreen Arabic report)

Wa kāna al-aminnu al-āmu lil-umami al-mutahidah qad abbara

And was the-secretary the-general to-nations the-united EMPH expressed

an shukrihi li-sūrya li-ta' āwniha ma'a al-lajnah

of thank.3SG.POSS.M to-Syria for-cooperation.3NSG with the-commission

Translation: The UN Secretary-General has expressed his gratitude to Syria for its cooperation with the commission.

Example 12 is the seventh and last main clause in the Tishreen Arabic report, which is titled 'Syria's cooperation satisfactory'. The clause displays a nominal marked structure. The sentence starts with an empty verb, kāna, followed by a noun, 'the US SecretaryGeneral', and then a verb, 'expressed'. The clause also displays an emphatic device, qad, which is commonly used in argumentative texts. Given its position, which is at the end of the Tishreen Arabic report, example 12 is expected to convey background, or old, information. However, New information is presented in rhematic position, i.e. 'gratitude'. The use of a marked thematic structure, an emphatic device and the presentation of New information in example 12 strongly suggests an attempt to positively influence the readers' perception of Syria and emphasize its good efforts. The analysis of the Tishreen Arabic report demonstrates the relationship between Theme-Rheme structure, the choice of Given and New information and the use of persuasive techniques to present a specific ideological representation of Syria. More specifically, Syria is portrayed as an innocent victim of unfounded accusations.

\section{Management of information}

By management of information, we refer to the role of news media as social institutions and the various mechanisms they use to engineer the public consent and manage their opinion. These mechanisms include restricting the flow and access of information by means of secrecy, security and censorship, hence only certain forms of knowledge and opinions are allowed, expressed and widely circulated (Fairclough 1995, Fairclough and Wodak 1997, Harré 1985, Hawthorn 1987, Herman and Chomsky 2002, Robins et al. 1987, and van Dijk 1997; 1998). The analysis of the data reveals that selecting certain linguistic terms as Themes or Rhemes and presenting certain information as Given or 
New play a significant role in managing information and shaping social representations. Examples 8 and 13 from the Al-Jazeera news media demonstrate this case.

8. Evidence found at the scene of the blast also included a tooth, probably of the bomber, which featured an unspecified 'distinguishing mark' on its crown, suggesting that he may not have been from Lebanon, the report said (Al-Jazeera English report).

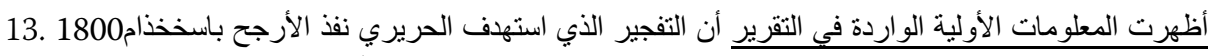

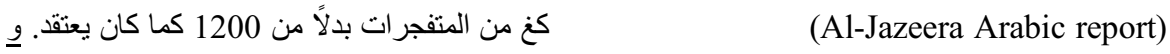

Wa azharat al-ma' lūmātu al-awalīatu al-wāridah fī at-taqrīin anna And showed the-information preliminary occurring in the-report that at-tafjīra al-ladhī istahdafa al-harīī nufidha' alá al-arjahi bi-istikhdāmi the-explosion which targeted al-Hariri carried.out on likely in-using $1800 \mathrm{~kg}$ mina al-mutafajirati badala ${ }^{\mathrm{n}}$ mina $1200 \mathrm{~kg}$ kamā kāna yu taqadu

$1800 \mathrm{~kg}$ of explosives instead of $1200 \mathrm{~kg}$ as was believed

Translation: Preliminary information in the [UN investigation] report revealed that the blast which targeted Hariri was most likely caused by $\mathbf{1 8 0 0} \mathrm{kg}$ of explosives instead of $1200 \mathrm{~kg}$, as was previously believed.

The English-language report was published on 26 September 2006 and the Arabiclanguage report was published the day after by the same online news media, Al-Jazeera. In example 8, 'evidence' functions as the Theme and presents Given information, see the previous discussion on example 8. New information is presented by the rhematic elements, 'tooth', 'unspecified distinguishing mark' and 'may not have been from' Lebanon, which imply the bomber's connection to Syria. The choices of Theme, Rheme, Given and New information in example 8 have a strong potential to trigger in the reader's mind a belief in Syria's involvement in Hariri's murder. However, a different social representation of Syria emerges from the analysis of example 13. The choice of New elements in thematic and rhematic positions, 'preliminary' and '1800kg' respectively, does not imply Syria's connection to Hariri's murder. Since the findings of the UN investigation are still at an early stage, any accusation against Syria is conceived in the Arabic version as no more than a speculation, which cannot be confirmed. This view is further supported by the lack of information; the terms 'evidence' and 'tooth' are not mentioned anywhere in the Al-Jazeera Arabic report. A similar view of Syria emerges from the analysis of the Tishreen and Al-Manar Arabic reports. These reports, for example, avoid using the term 'accusation' against Syria, thus rendering the link between Syria and Hariri's murder as weak.

Management of information is also observed in the analysis of the CNN news media. The choices of Theme, Rheme, Given and New information differ in the English- and Arabic-language news reports, as examples 14 and 15 demonstrate:

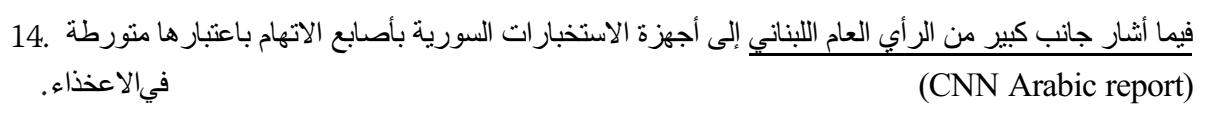

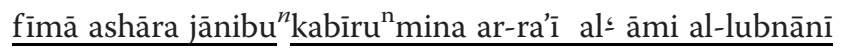


$\underline{\text { Meanwhile pointed side large of opinion general the-lebanese }}$

ilá ajhizati al-istikhbārāti as-sūrīati bi-așābi ' i al-itihami bi- ibārihā

to apparatuses intelligence the-Syrian in-fingers the-accusing in-considering.it

mutawrițah fī al-i 'idā'

involved in the-attack

Translation: Meanwhile, a large number of the Lebanese public opinion pointed to the Syrian intelligence services with accusing fingers considering it an accomplice in the attack.

15. The United States has suggested that the government of Syria is behind the Hariri murder... (CNN English report)

In example 14, 'a large number of the Lebanese public opinion' function as the Theme and present New information, which has not been mentioned before in this report. In example 15, 'The United States' function as the Theme and present New information. The information sequence in examples 14 and 15 is marked: unknown information is presented first followed by known information. The rhematic elements in both examples are known and predicted from previous reports. What the readers of these reports may not know is the party behind this accusation; whether it is the United Nations' investigation team, the majority of the Lebanese people, the Lebanese authority, Hariri's Future party or the United States. The United States justifies its accusations in the CNN English report by claiming to possess 'new leads' and 'growing evidence' to incriminate Syria, as is mentioned in the CNN English report. These leads are not elaborated upon and no real evidence is presented to support the United States' accusation. The choices of Theme-Rheme and GivenNew information in the CNN examples suggest that while the Arabic report presents the allegations against Syria in terms of a long-time opposition to the Syrian government possibly by Hariri's political party, the English report presents the US accusation in terms of 'evidence,' 'mounting leads' and 'well-established facts'. The analysis indicates that the choices made in the CNN English report are most likely to assert the readers' belief in Syria as a culprit of Hariri's murder, whereas, the ones made in the CNN Arabic version are less likely to emphasize this connection and belief. Examples 14 and 15 demonstrate the relationship between Theme-Rheme and Given-New structures and the management of information to construct specific ideological representations of Syria in the news.

\section{Summary}

To summarize, the analysis of the data reveals that the two systems of THEME and INFORMATION help to unravel the way news media manage information and shape social representations. With relevance to the selected reports, the analysis reveals that within the same news media embedded social representations are presented differently in accordance with the language of the target readers, i.e. English or Arabic. A positive representation of Syria emerges from the analysis of the selected Arabic reports, whereas a negative representation of Syria emerges from the analysis of the English ones. Specifically, most of the English news reports present the 'accusation' against Syria as New information in rhematic position and emphasize the 'evidence' against Syria of killing the Lebanese Prime Minister, Rafiq al-Hariri. This emphasis is carried out by various processes of thematization, naturalization, rationalization, habitualization, 
persuasion and management of information. The meaning-potential of these processes is explored, unlocked and identified using Halliday's two systems of THEME and INFORMATION. By contrast, the Arabic news reports present Syria's 'cooperation' as New information both in thematic and rhematic position, especially in headlines and subheadings. The 'accusation' against Syria is presented mostly as Given information and viewed in terms of ungrounded allegations by the government of the United States. Syria's innocence is inferred in the Arabic reports through various processes of thematization, repetition, positive association and the selection of Theme, Rheme, Given and New information. Nominal sentences and other marked thematic structures in Arabic are found to play a significant role in positively influencing the readers' perception of Syria.

The findings indicate that the language in which these reports are written influences the way Syria is presented in these reports. English news reports tend to favour a negative representation of Syria and readers are encouraged to perceive Syria as the logical perpetrator of Hariri's murder. Arabic news reports, by contrast, tend to favour a pro-Syria representation and readers are encouraged to perceive Syria as an innocent victim of unfounded accusations to murder the Lebanese politicians and destabilize the Lebanese government. Exceptions are mainly found in the Syrian state-run news agencies, Tishreen and Syria Times, where a pro-Syrian representation dominates their Arabic and English versions of the news. The results of the analysis substantiate the efficacy of Halliday's systems of THEME and INFORMATION in elucidating underlying ideologies and identifying the different representations of Syria in English and Arabic news reports.

\section{Conclusion}

Discursive processes such as thematization, naturalization, persuasion and management of information are techniques used by news media to influence the readers' perception of social realities. The relationship between these processes and Halliday's functional systems of THEME and INFORMATION is explored in 14 English and Arabic news reports. The analysis confirms the efficacy of Halliday's model, in English as well as in Arabic, to unlock the meaning-potential and identify underlying ideologies in news reports. Although this study focuses on a small number of reports, the results match closely with the ones found in a larger corpus of a 100 news reports collected and analysed in my doctoral thesis. Further research on the efficacy of Halliday's model in different text-types and/or genres can help to provide an insight into and validate the findings of this study. Another way forward would also be to investigate the thematic structures in translated English and Arabic texts.

\section{Endnotes}

${ }^{1}$ Arabic writing starts from the right to the left. To avoid confusion with word-for-word gloss, we also provide Romanization of Arabic sentences. The Romanization system adopted in this paper follows the United Nations Group of Experts on Geographical Names, see http://www.eki.ee/wgrs/rom1_ar.pdf. All examples in this paper will be presented in the same way, i.e. the example written in Arabic on the first line, followed by its transcription on the second, then the gloss on the third and finally the literary translation on the fourth. 
Abbreviations

1: $1^{\text {st }}$ person; 2: $2^{\text {nd }}$ person; 3: $3^{\text {rd }}$ person; ADT: adjunct; BBC: British Broadcasting Corporation; CD: communicative dynamism; CDA: critical discourse analysis; COMP: complement; CNN: Cable News Network; EMPH: emphatic device; F: feminine; FSP: Functional Sentence Perspective approach; GEN: genitive; M: masculine; N: neuter; POSS: possessive; PL: plural; S: singular; SANA: Syrian Arab News Agency; SBJ: subject; TAGs: Traditional Arab Grammarians; V: verb.

\section{Competing interests}

The author declares that she has no competing interests with regards to this work.

\section{Author's contribution}

LP is solely responsible for conceiving this study, collecting texts, conducting the proper analyses and writing this manuscript.

\section{Received: 20 November 2015 Accepted: 31 March 2016}

\section{Published online: 10 May 2016}

\section{References}

Abdul-Raof, H. 1998. Subject, theme, and agent in modern standard Arabic. London: Routledge.

Abu-Ghazaleh, N.N. 1983. Theme and the function of the verb in Palestinian Arabic narrative discourse, PhD dissertation. Florida: University of Florida.

Abu-Mansour, A.H. 1986. A functional analysis of sentence structure in standard Arabic: A three-level approach. Florida: University of Florida.

Adjémian, C. 1978. Theme, rheme and word order: Form Weil to present-day theories. Historiographia Linguistica 3: 253-273. Al-Jarim, A.A. 1953. The verbal sentence is the basis of expression in Arabic. The Academy of the Arabic Language 7: 347-350. Aziz, Y.Y. 1988. Theme-rheme organization and paragraph structure in standard Arabic. Word 39(2): 117-128. Baker, M. 1992. In other words: A course book on translation. London: Routledge.

Caffarel, A. 2006. A systemic functional grammar of French: From grammar to discourse. London: Continuum. Cantarino, V. 1974. Syntax of modern Arabic prose: The simple sentence, vol. 1. Bloomington: Indiana University Press. Chafe, W.L. 1974. Language and consciousness. Language 50: 111-133.

Chafe, W.L. 1976. Givenness, contrastiveness, definiteness, subjects, topics and point of view. In Subject and Topic, ed. C.N. Li, 25-55. London: Academic.

Fairclough, N. 1985. Critical and descriptive goals in discourse analysis. Journal of Pragmatics 9(6): 739-763. Fairclough, N. 1995. Critical discourse analysis. London: Longman.

Fairclough, N., and R. Wodak. 1997. Critical discourse analysis. In Discourse as social interaction. Discourse studies: A multidisciplinary introduction. Volume 2, ed. T.A. van Dijk, 258-285. London: Sage.

Firbas, J. 1966. On defining the theme in functional sentence analysis. Travaux Linguistiques de Prague 1: $267-280$.

Firbas, J. 1974. Some aspects of the Czechoslovak approach to problems of functional sentence perspective. In Papers on functional sentence perspective, ed. F. Daneš, 106-128. The Hague: Mouton.

Fowler, R., B. Hodge, G. Kress, and T. Trew. 1979. Language and control. London: Routledge.

Fowler, R. 1991. Language in the news: Discourse and ideology in the press. London: Routledge.

Fowler, R. 1996. Linguistic criticism, 2nd ed. Oxford: Oxford University Press.

Halliday, M.A.K. 1967. Notes on transitivity and theme in English. Part 2. Journal of Linguistics 3: 199-244.

Halliday, M.A.K. 1976. Theme and information in the English clause. In Halliday: System and function in language, ed. G. Kress, 174-188. London: Oxford University Press.

Halliday, M.A.K. 2004. An introduction to functional grammar, 3rd ed. London: Arnold.

Harré, R. 1985. Persuasion and manipulation. In Discourse and Communication, ed. T.A. van Dijk, 126-142. Berlin: Walter De Gruyter.

Hatim, B. 1989. Text linguistics in the didactics of translation: The case of the verbal and nominal clause types in Arabic International Review of Applied Linguistics in Language Teaching 27(2): 137-144.

Hawthorn, J. (ed.). 1987. Propaganda, persuasion and polemic. London: Arnold.

Herman, E.S., and N. Chomsky. 2002. Manufacturing consent: The political economy of the mass media. London: Pantheon.

Hodge, R, and Kress, G. 1993. Language as ideology. Second edition. London: Routledge.

Keenan, E.O., and B. Schieffelin. 1976. Foregrounding referents: A reconstruction of left dislocation in discourse. Berkeley Linguistics Society 2: 240-257.

Khalil, E.N. 2000. Grounding in English and Arabic News Discourse. Amsterdam: Benjamins.

McCabe, A. 1999. Theme and thematic patterns in Spanish and English history texts, Unpublished PhD dissertation. Birmingham: Aston University.

Moutaouakil, A. 1989. Pragmatic functions in a functional grammar of Arabic. Dordrecht: Foris Publications.

Munday, J. 1997. Systems in translation: a computer-assisted systemic analysis of the translation of García Márquez, Unpublished PhD dissertation. Bradford: University of Bradford.

Parkinson, D.B. 1981. VSO to SVO in Modern Standard Arabic: A study in diglossia syntax. Al-Arabiyya 14: 24-37.

Robins, K., F. Webster, and M. Pickering. 1987. Propaganda, information and social control. In Propaganda, persuasion and polemic, ed. J. Hawthorn, 1-17. London: Arnold.

Simpson, P. 1993. Language, ideology and point of view. London: Routledge.

Teruya, K. 2006. A Systemic functional grammar of Japanese, vol. 1. London: Continuum.

van Dijk, T.A. 1988. News as discourse. Hillsdale: Lawrence Erlbaum.

van Dijk, T.A. 1997. Discourse as social interaction. London: Sage.

van Dijk, T.A. 1998. Ideology: A multidisciplinary approach. London: Sage.

Wright, W. 1974. A grammar of the Arabic language. Beirut: Librairie de Liban.

Wodak, R. 2001. What CDA is about - A summary of its history, important concepts and its developments. In Methods of critical discourse analysis: Introducing qualitative methods, ed. R. Wodak and M. Meyer, 1-12. London: Sage. 